(2) Open Access Full Text Article

\title{
Poor outcome of laparoscopic cholecystectomy in patients with COPD: how determinant it is? [Letter]
}

Subrata Kumar Singha'

Habib MR Karim'

Antonio Esquinas ${ }^{2}$

'Department of Anaesthesia, AlIMS Raipur, Raipur, India; ${ }^{2} \mathrm{ICU}$, Hospital Morales, Murcia, Spain
Correspondence: Subrata Kumar Singha Department of Anaesthesia, AllMS, 3rd Floor, Major OT, Trauma Building, PO: Tatibandh, Raipur 492099, CG, India Email subratsingh@gmail.com
This article was published in the following Dove Press journal: International Journal of Chronic Obstructive Pulmonary Disease

\section{Dear editor}

We have read the study by Liao et al published in your journal with great interest. ${ }^{1}$ The article evaluates the effects of COPD on the outcome of laparoscopic cholecystectomy. Although COPD is a well-known risk for postoperative pulmonary complications, it is interesting to know this association from this matched study with a relatively larger sample. The authors' findings and conclusions are relevant, but we consider that a few other aspects need to be taken into account from the practical point of view.

Firstly, from the methodological point of view, although the cohort was matched for age and gender, their comorbidities were very much different and may have affected the outcome measures like use of supports, ie, vasopressors, hemodialysis (HD), mechanical ventilation (MV), intensive care unit (ICU) stay, etc. Inclusion of patients with only COPD in the COPD group or using multivariate analysis may have helped in determining the real impact caused by COPD. In addition, the time period considered, ie, 1997-2013, is too long and the management strategy, especially for COPD patients, has evolved/changed a lot, diluting the applicability in the current practice.

Secondly, the information on intraoperative and postoperative respiratory management is very crucial and is missing. Respiratory management in hypercapnic, emphysema patient during pneumoperitoneum, use of multimodal analgesia, especially regional analgesia techniques, neuromuscular blockade management can impact the postoperative pulmonary conditions and outcome. Similarly, preoperative optimization strategy for risk reduction taken, induction of COPD specific treatment, if any, is also equally important. ${ }^{2-4}$

Finally, information on whether the facility of HD, MV, ICU were there in all the hospitals included is critical. It is because, it can lead to a selection bias, management differences, as well as impact in the outcome.

A recent meta-analysis indicates that laparoscopic major gastrointestinal surgery in COPD patients is safe and has its own benefits including reduced overall postoperative pulmonary complications. ${ }^{5}$ However, proper patient selection is very important. ${ }^{5}$ While we very much welcome and accept the conclusion of the authors, we believe that the bad prognosis, ie, increased mortality and mechanical ventilation, shown and attributed to COPD needs to be judged in the 
above perspective too. Future study will be required to find out the impact of current management of COPD, its attribution toward postoperative mortality and subgroup of COPD patients who are more vulnerable.

\section{Disclosure}

The authors report no conflicts of interest in this communication.

\section{References}

1. Liao KM, Tseng CJ, Chen YC, Wang JJ, Ho CH. Outcomes of laparoscopic cholecystectomy in patients with and without COPD. Int J Chron Obstruct Pulmon Dis. 2019;14:1159-1165. Published 2019 May 27. doi:10.2147/COPD.S201866
2. Lumb A, Biercamp C. Chronic obstructive pulmonary disease and anaesthesia. Contin Educ Anaesth Crit Care Pain. 2013;14:1-5. doi:10.1093/bjaceaccp/mkt023

3. Khetarpal R, Bali K, Chatrath V, Bansal D. Anesthetic considerations in the patients of chronic obstructive pulmonary disease undergoing laparoscopic surgeries. Anesth Essays Res. 2016;10(1):7-12. doi: $10.4103 / 0259-1162.165500$

4. Numata T, Nakayama K, Fujii S, et al. Risk factors of postoperative pulmonary complications in patients with asthma and COPD. Published 2018 Jan 9. BMC Pulm Med. 2018;18(1):4. doi:10.1186/ s12890-017-0570-8

5. Guo Y, Cao F, Ding Y, et al. Laparoscopic major gastrointestinal surgery is safe for properly selected patient with COPD: a meta-analysis. Biomed Res Int. 2019;2019:8280358. doi:10.1155/2019/8280358

Dove Medical Press encourages responsible, free and frank academic debate. The content of the International Journal of Chronic Obstructive Pulmonary Disease 'letters to the editor' section does not necessarily represent the views of Dove Medical Press, its officers, agents, employees, related entities or the International Journal of Chronic Obstructive Pulmonary Disease editors. While all reasonable steps have been taken to confirm the content of each letter, Dove Medical Press accepts no liability in respect of the content of any letter, nor is it responsible for the content and accuracy of any letter to the editor.

International Journal of Chronic Obstructive Pulmonary Disease

\section{Publish your work in this journal}

The International Journal of COPD is an international, peer-reviewed journal of therapeutics and pharmacology focusing on concise rapid reporting of clinical studies and reviews in COPD. Special focus is given to the pathophysiological processes underlying the disease, intervention programs, patient focused education, and self management protocols. This journal is indexed on PubMed Central, MedLine and CAS. The manuscript management system is completely online and includes a very quick and fair peer-review system, which is all easy to use. Visit http://www.dovepress.com/testimonials.php to read real quotes from published authors. 